\title{
A general route for RuO2 deposition on metal oxides from RuO4
}

Kleiman-Shwarsctein, Alan; Laursen, Anders Bo; Cavalca, Filippo; Tang, Wei; Dahl, Søren; Chorkendorff, Ib

Published in:

Chemical Communications

Link to article, DOI:

$10.1039 / \mathrm{c} 1 \mathrm{cc} 16759 f$

Publication date:

2012

Document Version

Publisher's PDF, also known as Version of record

Link back to DTU Orbit

Citation (APA):

Kleiman-Shwarsctein, A., Laursen, A. B., Cavalca, F., Tang, W., Dahl, S., \& Chorkendorff, I. (2012). A general route for RuO2 deposition on metal oxides from RuO4. Chemical Communications, 48(7), 967-969.

https://doi.org/10.1039/c1cc16759f

\section{General rights}

Copyright and moral rights for the publications made accessible in the public portal are retained by the authors and/or other copyright owners and it is a condition of accessing publications that users recognise and abide by the legal requirements associated with these rights.

- Users may download and print one copy of any publication from the public portal for the purpose of private study or research.

- You may not further distribute the material or use it for any profit-making activity or commercial gain

- You may freely distribute the URL identifying the publication in the public portal

If you believe that this document breaches copyright please contact us providing details, and we will remove access to the work immediately and investigate your claim 


\title{
A general route for $\mathrm{RuO}_{2}$ deposition on metal oxides from $\mathrm{RuO}_{4}^{\dagger}$
}

\author{
Alan Kleiman-Shwarsctein, ${ }^{a}$ Anders B. Laursen, ${ }^{a}$ Filippo Cavalca, ${ }^{b}$ Wei Tang, ${ }^{a}$ Søren Dahl ${ }^{a}$ \\ and Ib Chorkendorff* $a$
}

Received 1st November 2011, Accepted 16th November 2011

DOI: $10.1039 / \mathrm{c} 1 \mathrm{cc16759f}$

A novel method for the deposition of $\mathrm{RuO}_{2}$ from $\mathrm{RuO}_{4}(\mathrm{~g})$ on diverse metal oxides has been developed by grafting dopamine onto the otherwise un-reactive metal oxide surface. Oxygen evolution reaction on $\mathrm{TiO}_{2}$ and the photoelectrochemical improvement of $\mathrm{WO}_{3}$ by deposition of $\mathrm{RuO}_{2}$ are just a few examples where this novel deposition method can be used.

Ruthenium dioxide (and metallic Ru) is widely used, for heterogeneous catalysis including oxidation reactions, reduction/hydrogenation reactions and ammonia synthesis; electrochemical/ photoelectrochemical reactions including Oxygen Evolution ${ }^{1}$ (OER), Hydrogen Evolution (HER), Oxygen Reduction (ORR, combined with Pt or Ir) ${ }^{2}$ as well as the chloro-alkali process to produce $\mathrm{Cl}_{2}$ and $\mathrm{NaOH}$. Other applications of $\mathrm{Ru}$ and $\mathrm{RuO}_{2}$ are in electronic materials where the high conductivity can be exploited for usage in DRAM capacitors, and battery materials. ${ }^{3} \mathrm{RuO}_{2}$ is especially regarded as being amongst the most promising electrode materials for super-capacitor ${ }^{4}$ applications.

Although there are many uses for $\mathrm{Ru}$ and $\mathrm{RuO}_{2}$ the incorporation, of this high-performance material, into industrial applications, is very limited due to the high cost of Ru. In many cases the overall cost of utilizing $\mathrm{RuO}_{2}$ could be decreased if an economically feasible method, which provides high stability and increased surface area, could be achieved. Furthermore, due to the great chemical resistance of $\mathrm{RuO}_{2}$ it is desirable to make thin coatings that can prevent the support material from being in contact with the chemical environment. Advances in chemical synthesis ${ }^{5,6}$ have provided mesoporous $\mathrm{RuO}_{2}$ materials, which provide an increased accessible surface area. In addition, conformal $\mathrm{RuO}_{2}$ coating can be achieved by atomic layer deposition (ALD). However, this requires expensive setups and in many cases exotic organic Ru complexes which need to be tailored depending on the metal oxide support that is being used.

Until now there was no general synthesis route in which $\mathrm{RuO}_{2}$ can be deposited from $\mathrm{RuO}_{4}(\mathrm{~g})$ onto a metal oxide, producing a thin semi-continuous, conformal or thin particulate coating that can be applied to any geometry and type of substrate

\footnotetext{
${ }^{a}$ Center for Individual Nanoparticle Functionality,

Department of Physics, Building 312, Fysikvej, Technical University of Denmark, DTU, DK-2800 Kgs. Lyngby, Denmark. E-mail: ibchork@fysik.dtu.dk

${ }^{b}$ Center for Electron Nanoscopy, Building 307, Fysikvej, Technical University of Denmark, DTU, DK-2800 Kgs. Lyngby, Denmark

$\dagger$ Electronic supplementary information (ESI) available. See DOI: $10.1039 / \mathrm{clcc} 16759 \mathrm{f}$
}

in an economical and easy way. Herein, we describe a 3 step method that is generally applicable to most metal oxides: (1) functionalization of the metal oxide host with a grafting agent, (2) reaction of the functionalized group with gas phase $\mathrm{RuO}_{4}$ and (3) post-treatment of the metal-oxide- $\mathrm{RuO}_{2}$ composite to obtain the required properties. This method is flexible, since the modification of these 3 steps could be used to include other families of support materials by changing the grafting molecule or the post-treatment conditions after deposition of $\mathrm{RuO}_{2}$.

Titanium dioxide (P25 or Degusa Vp Disp "W2730X" on fluorine doped tin oxide (FTO)) and tungsten trioxide (electrodeposited on FTO) were chosen as examples of metal oxide supports to show how this general $\mathrm{RuO}_{2}$ deposition method works. Many other metal oxides can also been functionalized with $\mathrm{RuO}_{2}$ and are shown in Table 1 as a reference. The functionalization (step 1, Scheme 1) of the metal oxide consists of the grafting of $20 \mathrm{mM}$ dopamine hydrochloride $\left((\mathrm{HO})_{2} \mathrm{C}_{6} \mathrm{H}_{3} \mathrm{CH}_{2} \mathrm{CH}_{2} \mathrm{NH}_{2} \mathrm{HCl}\right)$ onto the metal oxide, followed by washing of the metal oxide to remove non-grafted dopamine (see $\mathrm{ESI} \dagger$ for full details on the grafting procedure).

$\mathrm{X}$-Ray photoelectron spectroscopy of the N1s region for a dopamine functionalized $\mathrm{TiO}_{2}$ sample (Fig. S4a, ESI $\dagger$ ) shows two peaks at binding energies of 399.8 and $401.7 \mathrm{eV}$. The peak

Table 1 List of metal oxides that have been tested for $\mathrm{RuO}_{2}$ deposition

\begin{tabular}{ll}
\hline $\mathrm{RuO}_{2}$ deposition & $\mathrm{TiO}_{2}, \mathrm{SrTiO}_{3}, \mathrm{WO}_{3}, \mathrm{Cu}_{2} \mathrm{O}, \alpha-\mathrm{Fe}_{2} \mathrm{O}_{3}$, \\
& $\mathrm{Al}_{2} \mathrm{O}_{3}, \mathrm{Li}_{4} \mathrm{Ti}_{5} \mathrm{O}_{12}, \mathrm{MgAlO}, \mathrm{GaN}: \mathrm{ZnO}$ \\
$\mathrm{No} \mathrm{RuO}_{2}$ deposition & $\mathrm{SiO}_{2}, \mathrm{FTO}$ \\
\hline
\end{tabular}

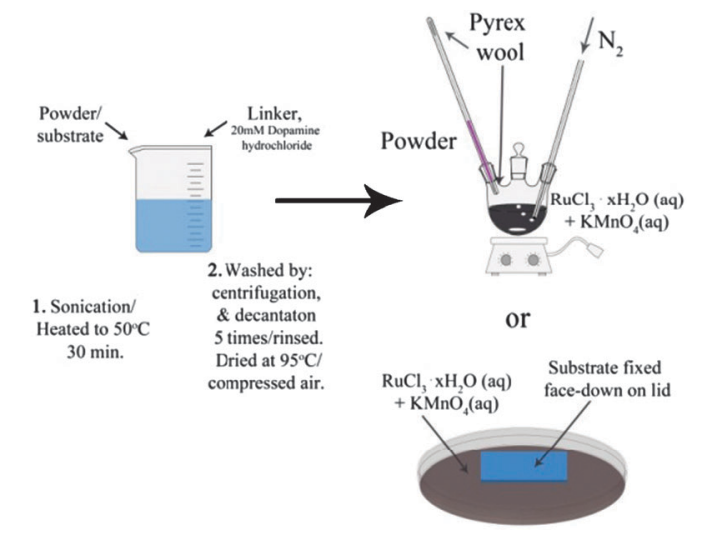

Scheme 1 Deposition process of $\mathrm{RuO}_{2}$ for powders and thin film metal oxides. 
at $399.8 \mathrm{eV}$ can be ascribed to the $\mathrm{NH}_{2}$ group of dopamine ${ }^{7}$ while the peak at $401.7 \mathrm{eV}$ could be related to $\mathrm{NH}_{3}{ }^{+}$species. ${ }^{7,8}$ The pristine $\mathrm{TiO}_{2}$ and the $\mathrm{TiO}_{2}$ with $\mathrm{RuO}_{2}$ before calcination (R0 and R1) show a peak at $400.1 \mathrm{eV}$ and after calcination (R3) at $400.4 \mathrm{eV}$, this peak could be related to adsorbed molecular $\mathrm{N}_{2}{ }^{9}$ and does not correspond to the binding energy reported for $\mathrm{N}$-doped $\mathrm{TiO}_{2}$. The XPS spectra is a clear indication that the dopamine is attached in a chelating bidentate structure via the diol groups to the uncoordinated titanium atoms at the surface of titanium dioxide, which is consistent with DFT calculations. ${ }^{7,10}$ The absorption of the dopamine on the $\mathrm{TiO}_{2}$ results in a slight color change as shown by the UV-Vis absorption properties (Fig. S5, ESI $\dagger$ ), in which the bandgap of $\mathrm{TiO}_{2}$ is decreased from $3.2 \mathrm{eV}$ to 3 . Changes in the absorption properties of $\mathrm{TiO}_{2}$ are due to the removal of band gap states in the $\mathrm{TiO}_{2}$ valence band ${ }^{7}$ caused by adsorption of dopamine.

Deposition of $\mathrm{RuO}_{2}$ on the metal oxides is done by a new method, in which gas phase in situ generated $\mathrm{RuO}_{4}$ is reacted with the dopamine functionalized metal oxide; this methodology has never been reported in literature before. Previous work in this area was limited to biological samples, ${ }^{11}$ polymers ${ }^{12}$ and etched metal surfaces ${ }^{12}$ since most metal oxides will not reduce $\mathrm{RuO}_{4}$ to $\mathrm{RuO}_{2}$ and therefore the $\mathrm{RuO}_{2}$ will not be deposited (see ESI $\dagger$ ). $\mathrm{RuO}_{4}$ was synthesized by in situ oxidation ${ }^{12}$ of $\mathrm{RuCl}_{3}$ with $\mathrm{KMnO}_{4}$ in a closed container, such that the toxic $\mathrm{RuO}_{4}$ gas evolves from the reaction mixture and reacts with the functionalized metal oxide.

Consideration of the type of support must be taken into account when delivering the gas phase $\mathrm{RuO}_{4}$, so that there are no gas diffusion limitations to the surface in order to ensure a homogeneous distribution of the $\mathrm{RuO}_{2}$ on the sample. Thin film substrates used were attached to the lid of a pyrex crystallizer (coating by convection of $\mathrm{RuO}_{4}(\mathrm{~g})$ )), while powders were packed in a pressurized glass tube flow reactor (forced flow, due to mass transport limitations). The loading of $\mathrm{RuO}_{2}$ can be controlled by the amount of $\mathrm{RuO}_{4}(\mathrm{~g})$ that is generated in situ by controlling the amount of $\mathrm{RuCl}_{3}$ and $\mathrm{KMnO}_{4}$ used or by repeating the deposition process several times (safety precautions and deposition details given in ESI $\dagger$ ). $\mathrm{RuO}_{4}$ in the gas phase will react with organics such as Kapton ${ }^{\circledR}$, phenol and paraffin, but will not be reactive to most metal oxides. This is clear from control experiments, which we have performed -in which $\boldsymbol{n} \boldsymbol{\mathrm { RuO } _ { 2 }}$ is observed on the non-functionalized $\mathrm{TiO}_{2}$ and $\mathrm{WO}_{3}$ samples; results that were also observed by Rolison et al. ${ }^{12}$ However in the case when dopamine is grafted to a great variety of metal oxides, which can be coated with hydrated $\mathrm{RuO}_{2}$ (Table 1), $\mathrm{SiO}_{2}$ and FTO could not be coated with $\mathrm{RuO}_{2}$ since dopamine adsorbs weakly on these substrates, however by using a different grafting agent they could be functionalized.

After deposition of $\mathrm{RuO}_{2}$ on the functionalized metal oxides, a distinct color change is observed, indicative of the deposition of $\mathrm{Ru} / \mathrm{RuO}_{x}$ (see photography S1, and UV-VIS S5, ESI $\dagger$ ). STEM HAADF imaging (Fig. 1a) shows a P25-Dopamine particle that has been reacted with $\mathrm{RuO}_{4}(\mathrm{~g})$; STEM EDX mapping shows the ruthenium distribution on the $\mathrm{TiO}_{2}$ particle: the brighter contrast in the image corresponds to that of $\mathrm{Ru}$ nanoclusters covering the darker $\mathrm{TiO}_{2}$ particle. X-Ray diffraction patterns of $\mathrm{TiO}_{2}$ can only be indexed to anatase and rutile phases (S2) indicating that the Ru deposit is not crystalline or/and is
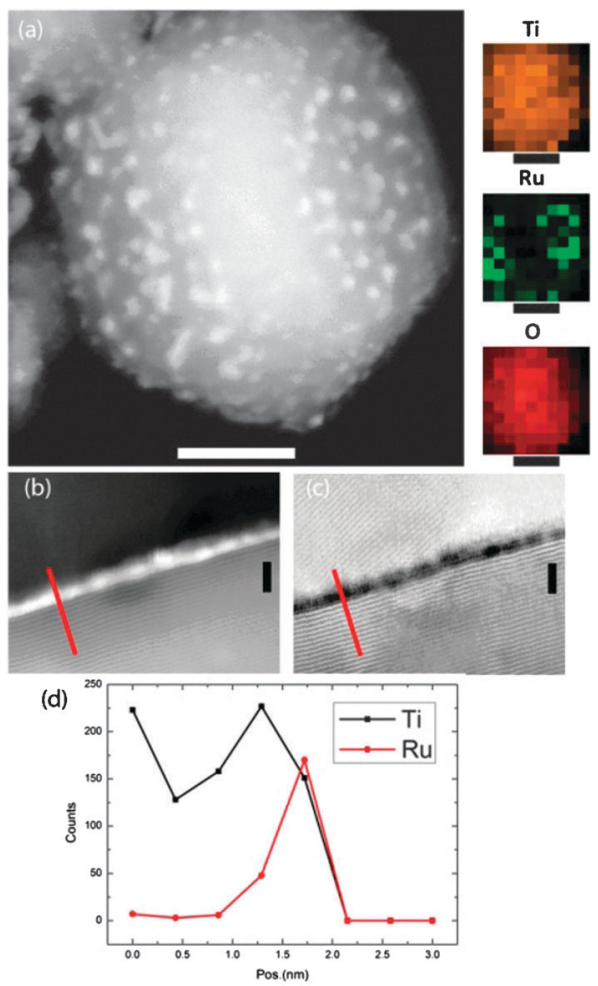

Fig. 1 (a) STEM HAADF image of $\mathrm{P} 25 \mathrm{TiO}_{2}$ with $\mathrm{RuO}_{2}$ deposition and EDX elemental map, prior to calcination, scale bar $5 \mathrm{~nm}$. (b-c) STEM HAADF and bright field of a $\mathrm{RuO}_{2}$ layer on a (123) anatase $\mathrm{TiO}_{2}$ surface after $450{ }^{\circ} \mathrm{C}$ calcination, scale bar $1 \mathrm{~nm}$; and (d) EDX spectrum profile acquired along the red line in $(b-c)$.

present in minute amounts or as small particles. Once the sample is calcined at $450{ }^{\circ} \mathrm{C}$ in air, STEM (Fig. 1b) reveals that $\mathrm{RuO}_{2}$ predominantly covers the surface of the $\mathrm{TiO}_{2}$ nanoparticle and is sintered into large homogeneous amorphous $\sim 1 \mathrm{~nm}$ thick layers. The predominantly small cluster from the uncalcined sample disappears leaving behind an empty $\mathrm{TiO}_{2}$ surface and a very sharp interface where $\mathrm{RuO}_{2}$ is present. Due to the higher $\mathrm{Z}$ number, $\mathrm{Ru}$ appears brighter in the HAADF image and darker in the corresponding $\mathrm{BF}$ image. Lattice fringes on the lower side of Fig. $1 \mathrm{~b}$ and $\mathrm{c}$ relate to the $\mathrm{TiO}_{2}$ particle where $\mathrm{RuO}_{2}$ is deposited, while the ones appearing on the uppermost side come from another particle at a different height. STEM EDX line scans performed on the calcined sample show that all of the $\mathrm{RuO}_{2}$ is present at the $\mathrm{TiO}_{2}$ grain boundaries. X-Ray diffraction patterns of the sample calcined at $450{ }^{\circ} \mathrm{C}$ do not show any $\mathrm{RuO}_{2}$ features but show a decreased crystallinity of the $\mathrm{TiO}_{2}$.

XPS spectra (Fig. S4d, e R2, further details in ESI $\dagger$ ) of the C 1s-Ru 3d XPS region show two peaks at 281.2 and $282.5 \mathrm{eV}$ in the $\mathrm{Ru} 3 \mathrm{~d} 5 / 2$ region and the corresponding peaks in the $\mathrm{Ru}$ $3 \mathrm{~d} 3 / 2$ at 285.7 , and $287 \mathrm{eV}$ corresponding to $\mathrm{Ru}^{3+}$ or hydrated $\mathrm{RuO}_{2},{ }^{13}$ and $\mathrm{Ru}^{6+}$ respectively; ${ }^{14,15}$ the $\mathrm{C} 1 \mathrm{~s}$ region shows two peaks at $284.9 \mathrm{eV}$ (advantageous carbon) and a second carbon peak at $288.8 \mathrm{eV} .{ }^{14}$ Upon calcination at $250{ }^{\circ} \mathrm{C}$ (Fig. S4d, f R3, ESI $\dagger$ ) the XPS spectra show peaks at 280.2 and $281.3 \mathrm{eV}$ for the $\mathrm{Ru} 3 \mathrm{~d} 5 / 2$ and 284.7 and $285.9 \mathrm{eV}$ for $\mathrm{Ru} 3 \mathrm{~d} 3 / 2$ corresponding to $\mathrm{Ru}^{4+}$ and $\mathrm{Ru}^{3+}$ or hydrated $\mathrm{RuO}_{2}{ }^{13}$ respectively. The $\mathrm{C} 1 \mathrm{~s}$ region has the advantageous carbon peak at $285.3 \mathrm{eV}$ and a second carbon peak at $288.7 \mathrm{eV}$. 

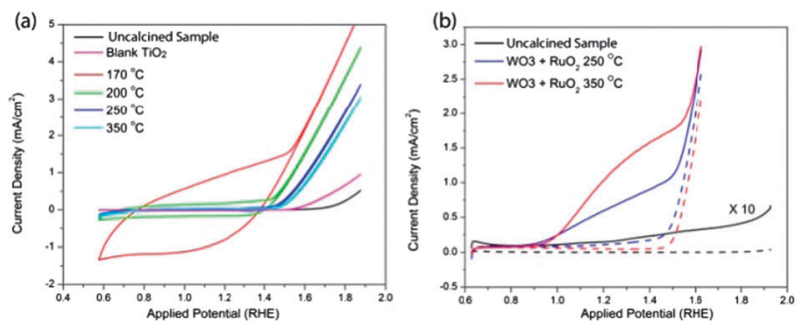

Fig. 2 (a) Cyclic Voltammogram of $\mathrm{TiO}_{2}$ on the FTO substrate with and without $\mathrm{RuO}_{2}$ in $1 \mathrm{M} \mathrm{NaOH}$, (b) cyclic voltammogram of electrodeposited $\mathrm{WO}_{3}$ on FTO with $\mathrm{RuO}_{2}$ calcined at $250{ }^{\circ} \mathrm{C}$ (blue) and $350{ }^{\circ} \mathrm{C}$ (red) and without $\mathrm{RuO}_{2}$ (black) in $1 \mathrm{M} \mathrm{HClO}_{4}$. Dashed lines show the response in the dark, while continuous lines show the photoresponse. Photocurrent of $\mathrm{WO}_{3}$ without $\mathrm{RuO}_{2}$ (black) has been scaled to 10 times its original value.

As one of the many potential applications for this $\mathrm{RuO}_{2}$ coating, the electrochemical performance towards OER was tested using spin coated $\mathrm{TiO}_{2}$ electrodes on FTO as a function of calcination temperature (see ESI $\dagger$ ). From Fig. 2a it can be seen that activity for OER is negligible for the uncalcined sample at $100{ }^{\circ} \mathrm{C}$ (data not shown). At $170{ }^{\circ} \mathrm{C}$ the sample has the highest OER activity and also shows hysteresis, which is indicative of proton intercalation into the $\mathrm{RuO}_{2}{ }^{4}$ However, at higher calcination temperatures the intercalation is decreased and the OER performance decreases due to a reduction in the electrochemical active ${ }^{12}$ area due to sintering of the $\mathrm{RuO}_{2}$. The latter is verified by observations from the TEM studies (Fig. 1). The overpotentials at $1 \mathrm{~mA} \mathrm{~cm}^{-2}$ and $0.1 \mathrm{~mA} \mathrm{~cm}^{-2}$ observed for OER are $\sim 250 \mathrm{mV}$ and $\sim 220 \mathrm{mV}$, respectively, which is the range of that reported for $\mathrm{RuO}_{2}$ and $\mathrm{RuO}_{2}$ alloys $^{16-19}\left(160-280 \mathrm{mV}^{12}\right)$.

The photocatalytic performance of $\mathrm{WO}_{3}$ with and without $\mathrm{RuO}_{2}$ was tested as another example of the application of the $\mathrm{RuO}_{2}$ deposition method being applicable to photocatalysts (see ESI $\dagger$ ). From Fig. $2 b$ it can be observed that the OER performance of $\mathrm{WO}_{3}$ in the dark (black dashed lines) is negligible, this is due in part to the poor OER kinetics on $\mathrm{WO}_{3}{ }^{20}$ as well as to the lack of holes in tungsten trioxide in the dark. Once $\mathrm{RuO}_{2}$ is deposited (dashed blue and red lines), an increase in current in the dark is observed, which is indicative of an increased OER activity in the dark due to the $\mathrm{RuO}_{2}$. This behavior would most probably be indicative of deposition of the $\mathrm{RuO}_{2}$ near the back contact where there is a lower resistance for OER due to pinholes in the $\mathrm{WO}_{3}$, since light would be needed for photoconduction of carriers through the $\mathrm{WO}_{3}$. In the case of the photoactivity of the $\mathrm{WO}_{3}$, the addition of $\mathrm{RuO}_{2}$ increased the PEC performance (blue and red curves) as compared to the $\mathrm{WO}_{3}$ sample without $\mathrm{RuO}_{2}$ (black curve, magnified 10 times). We can observe that the photocurrent onset potential of the samples with $\mathrm{RuO}_{2}$ is $\sim 1.0 \mathrm{~V} v s$. RHE as compared to $\sim 1.2 \mathrm{~V} v s$. RHE for the $\mathrm{WO}_{3}$ sample with no $\mathrm{RuO}_{2}$. This reduction in the onset potential for photocurrent is indicative that the OER reaction is being efficiently catalyzed when $\mathrm{RuO}_{2}$ is deposited on the photocatalyst.

A general route for $\mathrm{RuO}_{2}$ deposition on metal oxides from gas phase $\mathrm{RuO}_{4}$ has been developed by a simple 3 step process, in which a reactive moiety such as dopamine is grafted to the metal oxide and afterwards reacted with $\mathrm{RuO}_{4}(\mathrm{~g})$ to form $\mathrm{RuO}_{2}$. This application of the deposition process to synthesize supported $\mathrm{RuO}_{2}$ is of great interest for many catalysis and energy storage applications. Two examples have been showcased to demonstrate some of the potential applications that this method has. (1) The deposition of $\mathrm{RuO}_{2}$ on $\mathrm{TiO}_{2}$ as an OER catalyst has been shown to give similar results to those found in the literature and TEM microscopy has shown that small $\mathrm{RuO}_{2}$ clusters with a very homogenous coverage can be deposited utilizing this method. (2) The application of $\mathrm{RuO}_{2}$ as an OER catalyst in combination with $\mathrm{WO}_{3}$ as a photocatalyst has shown a superb improvement in performance by the deposition of $\mathrm{RuO}_{2}$. These two examples show just how versatile and universal the deposition method of $\mathrm{RuO}_{2}$ described in this communication is and some of the possible applications for catalysis in the renewable energy area.

This work was supported by the "Catalysis for Sustainable Energy" (CASE) research initiative, which is funded by the Danish Ministry of Science, Technology and Innovation. Center for Individual Nanoparticle Functionality is funded by The Danish National Research Foundation. A.K.S would like to thank the Hans Christian Ørsted fellowship. The authors would like to thank Dr Lone Bech and Mr John Larsen for technical assistance.

\section{Notes and references}

1 S. Trasatti, Electrochim. Acta, 1984, 29, 1503-1512.

2 I. M. Kodintsev, S. Trasatti, M. Rubel, A. Wieckowski and N. Kaufher, Langmuir, 1992, 8, 283-290.

3 Y. S. Hu, Y. G. Guo, R. Dominko, M. Gaberscek, J. Jamnik and J. Maier, Adv. Mater., 2007, 19, 1963-1966.

4 J. P. Zheng, P. J. Cygan and T. R. Jow, J. Electrochem. Soc., 1995, 142, 2699-2703.

5 S. H. Oh and L. F. Nazar, J. Mater. Chem., 2010, 20, 3834-3839.

6 J. V. Ryan, A. D. Berry, M. L. Anderson, J. W. Long, R. M. Stroud, V. M. Cepak, V. M. Browning, D. R. Rolison and C. I. Merzbacher, Nature, 2000, 406, 169-172.

7 K. Syres, A. Thomas, F. Bondino, M. Malvestuto and M. Gratzel, Langmuir, 2010, 26, 14548-14555.

8 Y. Zubavichus, O. Fuchs, L. Weinhardt, C. Heske, E. Umbach, J. D. Denlinger and M. Grunze, Radiat. Res., 2004, 161, 346-358.

9 J. M. Mwabora, T. Lindgren, E. Avendano, T. F. Jaramillo, J. Lu, S. E. Lindquist and C. G. Granqvist, J. Phys. Chem. B, 2004, 108, 20193-20198.

10 M. Vega-Arroyo, P. R. LeBreton, T. Rajh, P. Zapol and L. A. Curtiss, Chem. Phys. Lett., 2005, 406, 306-311.

11 P. Gaylarde and I. Sarkany, Science, 1968, 161, 1157-1158.

12 K. E. Swider-Lyons, C. T. Love and D. R. Rolison, J. Electrochem. Soc., 2005, 152, C158-C162.

13 K. S. Kim and N. Winograd, J. Catal., 1974, 35, 66-72.

14 J. Holm, H. Glanneskog and C. Ekberg, J. Nucl. Mater., 2009, 392, $55-62$.

15 S. Bhaskar, P. S. Dobal, S. B. Majumder and R. S. Katiyar, J. Appl. Phys., 2001, 89, 2987-2992.

16 Y. H. Fang and Z. P. Liu, J. Am. Chem. Soc., 2010, 132, 18214-18222.

17 P. Castelli, S. Trasatti, F. H. Pollak and W. E. Ogrady, J. Electroanal. Chem., 1986, 210, 189-194.

18 M. H. Miles, E. A. Klaus, B. P. Gunn, J. R. Locker and W. E. Serafin, Electrochim. Acta, 1978, 23, 521-526.

19 J. F. C. Boodts and S. Trasatti, J. Electrochem. Soc., 1990, 137, 3784-3789.

20 A. C. C. Tseung and S. Jasem, Electrochim. Acta, 1977, 22, 31-34. 